\title{
Influence of examiner's clinical experience on the reproducibility and accuracy of radiographic examination in detecting occlusal caries
}

\author{
Michele Baffi Diniz • Jonas Almeida Rodrigues • \\ Klaus W. Neuhaus • Rita C. L. Cordeiro • Adrian Lussi
}

Received: 23 March 2009 /Accepted: 21 July 2009 /Published online: 8 August 2009

(C) Springer-Verlag 2009

\begin{abstract}
The aim of this in vitro study was to assess the influence of varying examiner's clinical experience on the reproducibility and accuracy of radiographic examination for occlusal caries detection. Standardized bitewing radiographs were obtained from 166 permanent molars. Radiographic examination was performed by final-year dental students from two universities (A, $n=5 ; \mathrm{B}, n=5)$ and by dentists with 5 to 7 years of experience who work in two different countries $(\mathrm{C}, n=5 ; \mathrm{D}, n=5)$. All examinations were repeated after 1 -week interval. The teeth were histologically prepared and assessed for caries extension. For intraexaminer reproducibility, the unweighted kappa
\end{abstract}

\author{
M. B. Diniz • R. C. L. Cordeiro \\ Department of Pediatric Dentistry, \\ Araraquara School of Dentistry, \\ São Paulo State University (UNESP), \\ Araraquara, São Paulo, Brazil \\ R. C. L. Cordeiro \\ e-mail: ritacord@foar.unesp.br
}

M. B. Diniz $\cdot$ J. A. Rodrigues $\cdot$ K. W. Neuhaus $\cdot$ A. Lussi Department of Preventive, Restorative, and Pediatric Dentistry,

School of Dental Medicine, University of Bern,

Bern, Switzerland

J. A. Rodrigues

e-mail: jonas.rodrigues@zmk.unibe.ch

K. W. Neuhaus

e-mail: klaus.neuhaus@zmk.unibe.ch

A. Lussi

e-mail: adrian.lussi@zmk.unibe.ch

M. B. Diniz $(\bowtie)$

Departamento de Clínica Infantil,

Faculdade de Odontologia de Araraquara,

Rua Humaitá, 1680 Centro,

14801-903 Araraquara, São Paulo, Brazil

e-mail: mibdiniz@hotmail.com values were: A (0.11-0.40), B (0.12-0.33), C (0.47-0.58), and $\mathrm{D}(0.42-0.71)$. Interexaminer reproducibility statistics were computed based on means $\pm \mathrm{SD}$ of unweighted kappa values: A (0.07 \pm 0.05$), \mathrm{B}(0.12 \pm 0.09), \mathrm{C}(0.24 \pm 0.08)$, and $\mathrm{D}(0.33 \pm 0.10)$. Sensitivity, specificity, and accuracy were calculated at $\mathrm{D}_{1}$ and $\mathrm{D}_{3}$ thresholds and compared by performing McNemar test $(p=0.05)$. $\mathrm{D}_{1}$ sensitivity ranged between 0.29 and 0.75 and specificity between 0.24 and $0.85 . \mathrm{D}_{3}$ specificity was moderate to high (between 0.62 and 0.95 ) for all groups, with statistically significant difference between the dentists groups (C and D). Sensitivity was low to moderate (between 0.21 and 0.57 ) with statistically significant difference for groups B and D. Accuracy was similar for all groups (0.55). Spearman's correlations were: A $(0.12), \mathrm{B}(0.24), \mathrm{C}(0.30)$, and D (0.38). In conclusion, the reproducibility of radiographic examination was influenced by the examiner's clinical experience, training, and dental education as well as the accuracy in detecting occlusal caries.

Keywords Dental caries - Occlusal caries detection . Radiographic caries diagnosis · Clinical experience . Bitewing radiographs

\section{Introduction}

Caries diagnosis is an important aspect in the prevention and treatment of lesions and a difficult mission in dentistry [1]. Radiographic examination has been widely used in dental practice as a supplement to the visual inspection for caries detection $[2,3]$. However, it has been shown that radiographs present good performance only to detect dentine lesions [4-6]. The consciousness and the experience of "hidden caries," which is a caries lesion seen in 
dentine by radiographic examination and clinically presents as sound or demineralized occlusal enamel, have promoted the clinician's attention to the value of radiographic examination for occlusal surfaces [7].

Nevertheless, occlusal surface radiographs represent a two-dimensional image of a three-dimensional tooth, making the detection of mineral loss in the enamel difficult, especially when it is hidden by sound tooth tissue or the caries lesion is superimposed onto the dentine due to the complex anatomy of the occlusal area $[2,8]$. In addition, a failure of the radiographic examination is the false-negative and false-positive errors, which could make it difficult to decide on patient management and treatment $[2,3]$. The examiner's experience or inexperience in detecting occlusal caries by bitewing radiographs is also a factor [9]. Some studies have shown that experience regarding radiographic analysis differs among clinicians to detect approximal or occlusal caries $[2,10]$. There are some reports in the literature referring to student skills in detecting caries from bitewing radiographs and comparing it to faculty dentists or practitioners [11-13].

Since invasive treatment is usually required when a caries lesion extends into dentine, it is essential to analyze the performance of radiographic examination for occlusal caries detection. The great variation existing between examiners, mainly at radiographic detection of occlusal caries, brings up the interest to research the performance between different groups of examiners of higher and lower level of experience. Consequently, the purpose of this in vitro study was to assess the influence of examiner's clinical experience (dental students versus experienced dentists) from two different countries on the reproducibility and accuracy of radiographic examination in detecting occlusal caries lesions.

\section{Material and methods}

Sample preparation

One hundred and sixty-six human third permanent molars were selected from a pool of extracted teeth with varying condition from sound to carious on occlusal surfaces. They were stored frozen at $-20^{\circ} \mathrm{C}$ until use and during the experiments. Teeth with caries and noncaries defects on buccal, lingual, and proximal surfaces were not selected. All teeth were extracted by dental practitioners in Switzerland (no water fluoridation, $250 \mathrm{ppm} \mathrm{F}^{-}$in table salt). Prior to extraction (which was scheduled for reasons other than the study), the patients were informed about the use of their teeth for research purposes, and their consent was obtained.

The teeth were defrosted for $3 \mathrm{~h}$, and the calculus and debris were removed using a scaler (Cavitron). They were cleaned for $15 \mathrm{~s}$ with water and toothbrush (Trisa ultrasupersensitive, Triengen, Switzerland) and for $10 \mathrm{~s}$ with a water powder jet cleaner (PROPHYflex II, KaVo, Biberach, Germany) with sodium hydrogen carbonate powder. In order not to have powder remnants in the fissure, the teeth were then rinsed off with a three-in-one syringe for $10 \mathrm{~s}$ [14].

Photographs of the occlusal surfaces were taken at a $\times 6.25$ magnification using a light microscope (Leica DC300, Leica, Heerbrugg, Switzerland) equipped with a video camera linked to a computer (Leica M420, Leica, Heerbrugg, Switzerland) to select one specific area (sound or carious) from each tooth in the fissure surface as the test site. This is an important step to permit proper assessments of the same area by different examiners.

\section{Bitewing radiographs}

The teeth were then embedded in wax blocks, and standardized bitewing radiographs were taken using a fixed apparatus with a film holder, an X-ray machine (HDX Dental EZ, USA), and double Kodak Insight films $(22 \times 35 \mathrm{~mm}$, Kodak, Rochester, MN, USA $)$ at $65 \mathrm{kV}$, $7 \mathrm{~mA}$, and exposure time of $0.09 \mathrm{~s}$. The source-to-film distance was $22 \mathrm{~cm}$. Close to the object on the focus side, a $0.5-\mathrm{cm}$-wide plastic mold was placed to simulate soft tissues. All radiographs were processed by an automatic X-ray film developer XR 24 Pro (Dürr Dental, Bietigheim-Bissingen, Germany), placed in transparent cards, and identified.

\section{Examiners}

Four different groups of examiners assessed the bitewing radiographs twice, observing a 1-week interval between the analyses. The groups were arranged as follows:

Group A. Brazilian final-year dental students $(n=5)$

Group B. Swiss final-year dental students $(n=5)$

Group C. Brazilian dentists with 5 to 7 years of experience $(n=5)$

Group D. Swiss dentists with 5 to 7 years of experience $(n=5)$

The examiners did not receive an additional training or calibration in interpretation of bitewing radiographs. In fact, each group of examiners was equally instructed through oral orientation about the scores and interpretation for caries detection on radiographs before the examinations [15]. Each examiner performed the radiographic examination guided by black and white photographs printed in draft quality paper. Each photograph of the occlusal surface had a dot on the test site to allow the examiners to localize precisely the test site during the following analysis. This precaution was taken to avoid examiner bias toward the photographs. All the 
examiners independently analyzed the films using an X-ray viewer (Imatec Röntgentechnik, Switzerland) and an X-ray film magnifier (magnification $\times 2$; Svenska Dental Instrument, Sweden), in a dark room, to determine whether the occlusal surfaces under study showed: no radiolucency $(0)$, radiolucency in enamel (1), radiolucency in the outer half of dentine (2), and radiolucency in the inner half of dentine (3).

\section{Validation (gold standard)}

The teeth were ground longitudinally on a Knuth-Rotor polishing machine (Struers, Denmark) with silicone carbide paper of grain size $60 \mu \mathrm{m}$, cooled under tap water. To confirm the grinding process, teeth were analyzed under the microscope at a magnification of $\times 3.2$. When the test site was reached, papers of grain size 30,18 , and $10 \mu \mathrm{m}$ were used. The occlusal cut surfaces were photographed, and it was ensured that the caries lesion was not ground away. The tooth surfaces were then colored with saturated rhodamine B (Fluka, Buchs, Switzerland) dissolved in water. Sites were histologically assessed for caries extension according to the rhodamine $\mathrm{B}$ penetration (magnification $\times 10$ ) either into the enamel or both the enamel and the dentine tissues, according to Lussi et al. [16] in a five-point scale:

$\mathrm{D}_{0} \quad$ no caries

$\mathrm{D}_{1}$ caries extending up to halfway through the enamel

$\mathrm{D}_{2}$ caries in the inner half of enamel

$\mathrm{D}_{3}$ caries limited to the outer half of dentine

$\mathrm{D}_{4}$ caries extending into the inner half of dentine

\section{Statistical analysis}

Accuracy was calculated by means of sensitivity and specificity at $\mathrm{D}_{1}$ and $\mathrm{D}_{3}$ thresholds (MedCalc for Windows, version 9.3.0.0, Mariakerke, Belgium). $\mathrm{D}_{1}$ threshold considers enamel and dentine caries lesions as decayed, and $\mathrm{D}_{3}$ threshold considers only dentine caries lesions as decayed. McNemar test was applied to compare the performance of the different groups of examiners. The receiver operating characteristic (ROC) curve was also evaluated, in which the area beneath the ROC curve $\left(A_{\mathrm{z}}\right)$ indicated the quality of the observer performance. The closer to the upper left corner the curve is located, the better is the observer's performance. Diagnosis by chance will give an area of 0.5 , whereas perfect performance gives 1 . In general, values will be between these outer limits [8]. Pairwise comparison of ROC curves was performed at $\mathrm{D}_{1}$ and $\mathrm{D}_{3}$ thresholds.

Additionally, Spearman's correlation coefficient between the radiographic examination and the histological analysis was performed for the four groups of examiners.

Reproducibility was evaluated by means of interexaminer and intraexaminer agreement, and Cohen's unweighted kappa values were used [17]. Reproducibility indicates the closeness of the agreement between the results of measurements carried out under changed conditions of measurement [18]. Kappa values above 0.75 denoted excellent agreement, while values between 0.40 and 0.75 indicated good agreement, and less than 0.40 denote marginal agreement [19]. The means of kappa values of different groups of examiners were compared using the $t$ test. The level of significance was taken as $p<0.05$.

\section{Results}

In this study, from the 166 occlusal sites analyzed (one test site per tooth), the histological examination revealed that eight $(4.8 \%)$ were caries free $\left(\mathrm{D}_{0}\right) ; 12(7.2 \%)$ had caries extending up to halfway through the enamel $\left(\mathrm{D}_{1}\right)$; $69(41.6 \%)$ had caries extending in the inner half of enamel $\left(\mathrm{D}_{2}\right) ; 47(28.3 \%)$ had caries in the outer half of the dentine $\left(\mathrm{D}_{3}\right)$, and $30(18.1 \%)$ had deep dentinal caries $\left(\mathrm{D}_{4}\right)$.

The mean sensitivity, specificity, and accuracy are reported in Table 1. At $\mathrm{D}_{1}$ threshold, dentists from group D presented a significant lower sensitivity (0.29) and higher specificity $(0.85)$ than the three other groups. Dental students from group B achieved higher sensitivity

Table 1 Sensitivity, specificity, and accuracy of radiographic examination for caries detection of the different examiner groups

\begin{tabular}{|c|c|c|c|c|c|c|}
\hline \multirow[t]{2}{*}{ Examiners groups } & \multicolumn{2}{|c|}{ Sensitivity } & \multicolumn{2}{|c|}{ Specificity } & \multicolumn{2}{|c|}{ Accuracy } \\
\hline & $\mathrm{D}_{1}$ & $\mathrm{D}_{3}$ & $\mathrm{D}_{1}$ & $\mathrm{D}_{3}$ & $\mathrm{D}_{1}$ & $\mathrm{D}_{3}$ \\
\hline A & $0.54 \mathrm{a}$ & $0.21 \mathrm{a}$ & $0.43 \mathrm{a}$ & $0.88 \mathrm{a}$ & $0.53 \mathrm{a}$ & $0.57 \mathrm{a}$ \\
\hline $\mathrm{B}$ & $0.75 b$ & $0.57 \mathrm{~b}$ & $0.24 b$ & $0.62 b$ & $0.73 b$ & $0.60 \mathrm{a}, \mathrm{b}$ \\
\hline $\mathrm{C}$ & $0.37 \mathrm{c}$ & $0.22 \mathrm{a}$ & $0.54 \mathrm{a}$ & $0.95 \mathrm{c}$ & $0.38 \mathrm{c}$ & $0.61 \mathrm{~b}$ \\
\hline $\mathrm{D}$ & $0.29 \mathrm{~d}$ & $0.29 \mathrm{c}$ & $0.85 \mathrm{c}$ & $0.91 \mathrm{a}$ & $0.32 \mathrm{~d}$ & $0.62 b$ \\
\hline
\end{tabular}

$\mathrm{D}_{1}: \mathrm{D}_{0}=$ sound; $\mathrm{D}_{1}-\mathrm{D}_{4}=$ decayed; $\mathrm{D}_{3}: \mathrm{D}_{0}-\mathrm{D}_{2}=$ sound; $\mathrm{D}_{3}-\mathrm{D}_{4}=$ decayed; Within columns, significant differences are represented by different letters (McNemar test, $p=0.05$ ) 
(0.75) and lower specificity (0.24). However, the best value of accuracy (0.73) was presented by the group of students B. At $D_{3}$ threshold, groups A, C, and D presented lowest values of sensitivity (from 0.21 to 0.29 ) and group C the highest value of specificity (0.95), with statistically significant difference when compared to the other groups. For accuracy, there was statistically significant difference only among groups $\mathrm{A}, \mathrm{C}$, and D.

The ROC curve (Figs. 1 and 2) gives a graphic representation of the true-positive fraction (sensitivity) and the false-positive fraction. At $\mathrm{D}_{1}$ threshold, group $\mathrm{D}$ presented higher area under the ROC curve when compared to group $\mathrm{C}$. At $\mathrm{D}_{3}$ threshold, groups $\mathrm{B}, \mathrm{C}$, and $\mathrm{D}$ presented the highest areas under the ROC curve, with no statistically significant difference among them.

Spearman's correlation coefficient is presented in Table 2. Group D presented the highest correlation (0.38) when compared to the others, and group A presented the lowest correlation (0.12).

Reproducibilities are represented in Tables 3 and 4. Regarding interexaminer reproducibility (Table 3), statistics were computed based on means $\pm \mathrm{SD}$ of unweighted
Cohen's kappa values. Dentists from group D presented the highest kappa value $(0.33 \pm 0.10)$ comparing the groups. Overall, for the other three groups, the interexaminer agreement was considerably lower (varying from $0.07 \pm$ 0.05 to $0.24 \pm 0.08$ ). For intraexaminer reproducibility (Table 4), the unweighted Cohen's kappa values varied from 0.11 to 0.40 for group A, 0.12 to 0.33 for group B, 0.47 to 0.58 for group $\mathrm{C}$, and 0.42 to 0.71 for group $\mathrm{D}$.

\section{Discussion}

Few studies have evaluated the effect of the examiner's clinical experience on the performance of radiographic examination to detect occlusal caries lesion $[2,8,11,12$, $20,21]$. In this study, we aimed to evaluate the differences presented by dental students and general dental practitioners of two countries on occlusal caries detection using the same series of quality-controlled duplicated bitewing radiographs.

It is important to stress that occlusal surface radiographs represent a two-dimensional image of a three-dimensional
Fig. 1 ROC curves for the four groups at $\mathrm{D}_{3}$ threshold. The areas under ROC curve $\left(A_{\mathrm{z}}\right)$ are also shown. Different superscript letters mean statistically significance difference $(p<0.05)$
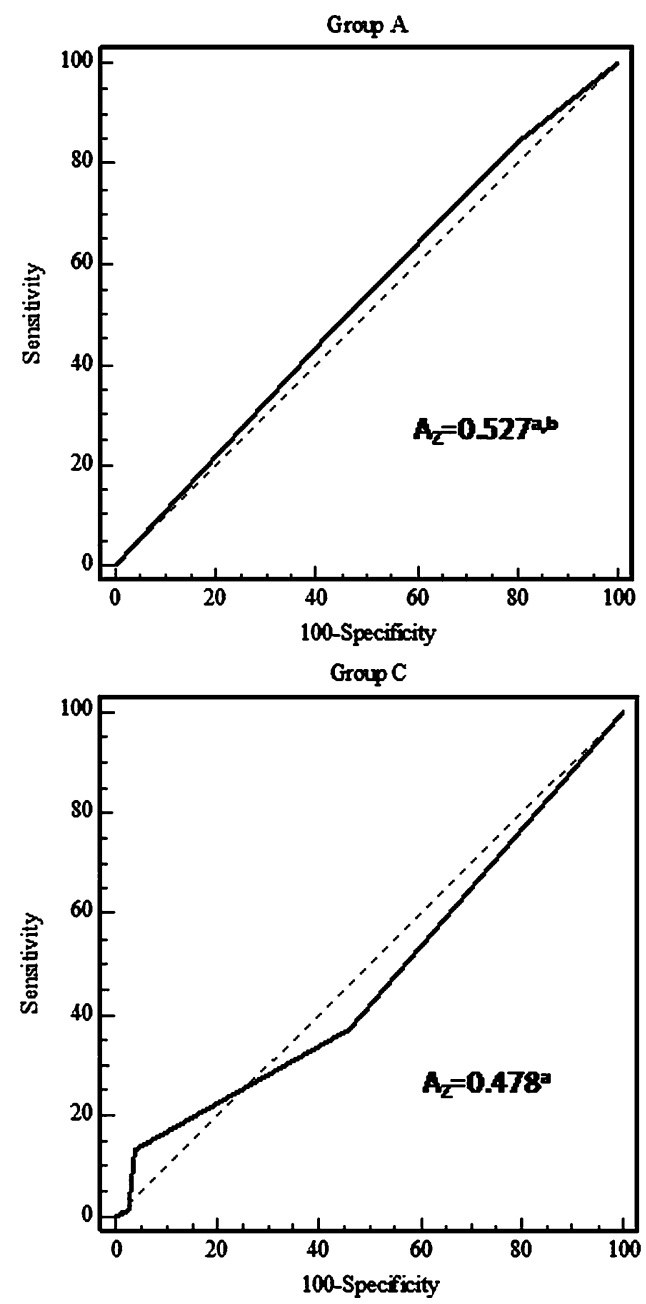

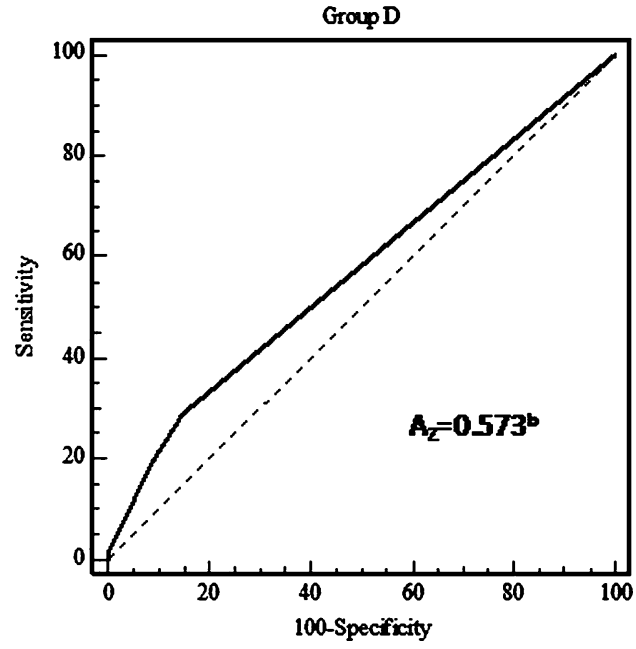


Fig. 2 ROC curves for the four groups at $\mathrm{D}_{3}$ threshold. The areas under ROC curve $\left(A_{\mathrm{z}}\right)$ are also shown. Different superscript letters mean statistically significance difference $(p<0.05)$
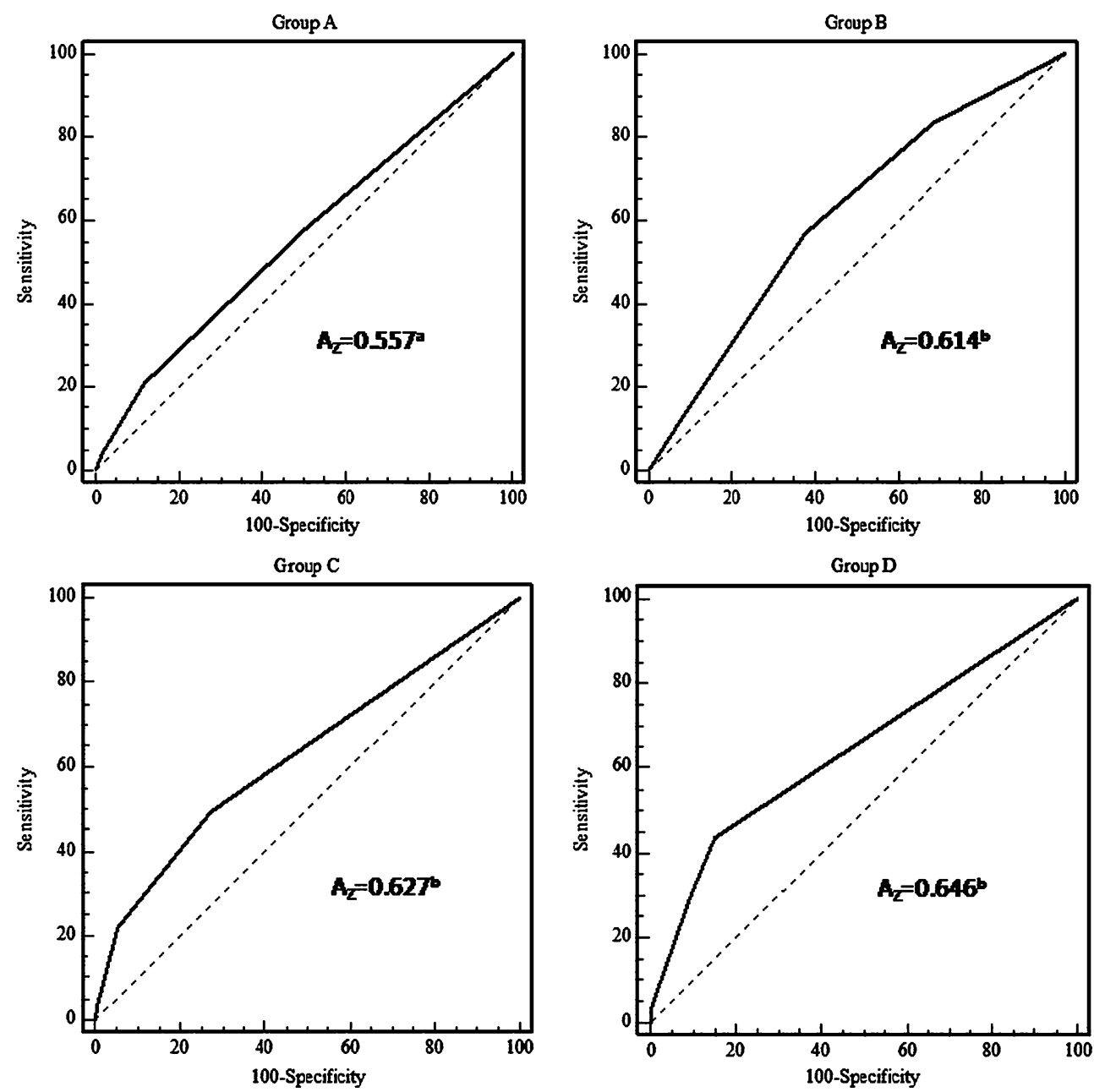

tooth, making the detection of mineral loss in the outer part of the enamel that is hidden by sound tooth structure difficult [8] or even the borderline between enamel and dentine [2]. A tendency to make false-positive scores is common, and this could be due to the Mach-band effect, which is an inclination to see a radiolucency in the dentineenamel junction where no dentine lesion is actually present [2]. This effect is a perceptual phenomenon, an enhancement of the contrast between a dark and a relatively lighter area which are sharply demarcated [22]. Besides, another

Table 2 Mean \pm SD of unweighted kappa values obtained for interexaminer reproducibility for the four groups

\begin{tabular}{lc}
\hline Examiner groups & Mean \pm SD of kappa values \\
\hline A & $0.07 \pm 0.05 \mathrm{a}$ \\
B & $0.12 \pm 0.09 \mathrm{a}$ \\
C & $0.24 \pm 0.08 \mathrm{~b}$ \\
D & $0.33 \pm 0.10 \mathrm{c}$ \\
\hline
\end{tabular}

Statistics were computed based on ten pairwise Cohen's kappa coefficient. Different letters mean statistically significant difference among values within the same column $(t$ test; $p<0.05)$ complicating factor could be explained by the fact that caries lesions located in pit and fissures might be superimposed onto the dentine radiographically due to the complex anatomy of the occlusal area [2].

For $\mathrm{D}_{1}$ threshold, the prevalence of caries was $95.2 \%$. In the present study, students of group B exhibited the highest value of sensitivity (0.75) and the lowest value of specificity (0.24). Students of group A presented better specificity (0.43) when compared to the students of group B. The different results presented here could be explained by the differences related to the student's dental education. Brazilian dental education generally consists of 5 to 5 years of instruction, while Swiss dental education consists of 5 years of instruction, with 2 years of medicine studies and 3 years of dentistry studies. Although students from group $B$ had different dental education when compared to the students from group A, they presented the ability to detect decayed occlusal surfaces on bitewing radiographs. However, they had the ability to detect sound surfaces as caries (false positive). On the other hand, dentists of groups $\mathrm{C}$ and $\mathrm{D}$ presented the highest values of specificity $(0.54$ and 0.85 , respectively) and lowest values of sensitivity (0.37 and 0.29 , respectively). These results might indicate that 
Table 3 Unweighted kappa values for intraexaminer reproducibility of the different examiners

\begin{tabular}{|c|c|c|c|c|c|c|c|}
\hline \multicolumn{2}{|c|}{ Group A } & \multicolumn{2}{|c|}{ Group B } & \multicolumn{2}{|c|}{ Group C } & \multicolumn{2}{|c|}{ Group D } \\
\hline Exam. & Kappa & Exam. & Kappa & Exam. & Kappa & Exam. & Kappa \\
\hline 1 & 0.21 & 1 & 0.25 & 1 & 0.50 & 1 & 0.49 \\
\hline 2 & 0.11 & 2 & 0.16 & 2 & 0.47 & 2 & 0.54 \\
\hline 3 & 0.23 & 3 & 0.33 & 3 & 0.54 & 3 & 0.47 \\
\hline 4 & 0.31 & 4 & 0.12 & 4 & 0.58 & 4 & 0.71 \\
\hline 5 & 0.40 & 5 & 0.31 & 5 & 0.50 & 5 & 0.42 \\
\hline
\end{tabular}

dentists are more willing to accept a lower level of sensitivity in exchange for a higher level of specific caries $[12,20]$. In other words, they are willing to not detect some caries lesions in order not to overtreat the disease since they have seen the long-term results of restoration placement. Quite the opposite, dental students have not had the experience of observing teeth over long periods of time and, consequently, they have not seen the long-term consequences of a restorative treatment [23, 24]. In contrast, dental students are more susceptible to classify any alteration on enamel as caries $[12,20]$. Besides, they had learned that all disease in oral cavity must be detected and treated, and, for them, missing a caries lesion is a huge error. Rocha et al. [25] in an in vitro study evaluating conventional bitewing radiographs for diagnosis of occlusal caries by a group of 13 dental students and a radiologist with more than 10 years of experience showed that students presented a low sensitivity $(0.21)$ and high specificity (1.00) and the radiologist presented moderate sensitivity (0.57) and high specificity (1.00). However, it should be highlighted that in the referred work the examiners were considered inexperienced students, and the professional had a renowned experience in radiology. Also, they received a special training before the examinations, different from the students and the professionals evaluated in our study. The results presented for $D_{1}$ threshold confirm that radiographic examination does not allow an early assessment of superficial lesions and also the inability of radiographs to detect lesions restricted to enamel [26].

For $\mathrm{D}_{3}$ threshold, the prevalence of caries was $46.4 \%$. The sensitivity was very low for groups A, C, and D (ranging from 0.21 to 0.29 ), with a statistically significant difference for group D. For group B, the sensitivity was

Table 4 Spearman's correlation coefficient for the different groups

\begin{tabular}{lc}
\hline Examiner groups & Spearman's correlation \\
\hline A & 0.12 \\
B & 0.24 \\
C & 0.30 \\
D & 0.38 \\
\hline
\end{tabular}

significantly moderate (0.57). However, the specificity values were high for groups $\mathrm{A}, \mathrm{C}$, and D (ranging from 0.88 to 0.95 ) and moderate for group B (0.62). Others studies had described low results for sensitivity concerning radiolucency into dentin [27-30]. These authors had observed sensitivity values ranging from 0.14 to 0.34 and specificity values ranging from 0.89 to 1.00 , with a prevalence of dentine caries ranging from $28 \%$ to $46 \%$. Ekstrand et al. [31], Rodrigues et al. [27], and Ashley et al. [30] had shown a specificity value of $1.00,0.97$, and 0.89 , respectively, when radiographic examination was performed to detect radiolucency to middle third of dentine of occlusal surfaces. Nevertheless, radiographs performed badly when compared with the results from previous studies. The poor performance of radiographs in this study may have been due to the very early nature of the lesions. In this study, only $18 \%$ of teeth with dentinal lesions had caries extending deeper than half of the depth of the dentine, while, in the studies of Lussi et al. [32] and Ricketts et al. [33], $36 \%$ to $67 \%$ of teeth with dentinal caries had deep lesions, and the sensitivity was recorded as a value around 0.62 . We can presume that, if the images had been electronically enhanced, it would be possible to increase the validity of the radiographic examination in this study. This was also suggested by Ashley et al. [30]. It could also be observed that the dental practitioners and students had, as a group, a similar diagnostic accuracy (ranging from 0.57 to 0.62 ) for observing and recognizing dentine caries from bitewing radiographs. This is in agreement with Mileman and van den Hout [20].

Occlusal deep dentinal caries lesions should be correctly detected in need of operative treatment; this way, a high sensitivity is preferred [34]. However, the present results in this study showed extremely lower sensitivity values, especially for the professional groups. Based on that, we could observe that dentists were not able to detect dentine caries in the occlusal surfaces from bitewing radiographs. Another study had shown that dentists expressed doubts about the value of the radiograph in occlusal caries detection [8, 35]. Caution must be taken when decisions to restore are based on bitewing radiographs. The disease prevalence in our sample was high $(95.2 \%$ caries with $46.4 \%$ dentine caries). According to Downer [36], a 
positive correlation between the disease prevalence and the sensitivity of a diagnostic method has been demonstrated. In this study, we observed a negative correlation since a low sensitivity for dentine caries was observed for all groups.

Although the bitewing radiograph is indicated for approximal caries detection, in our study, Spearman's correlation coefficients were lower for all the groups, demonstrating that the bitewing radiographic examination was not a good method to detect occlusal caries lesions. Rodrigues et al. [27] found a Spearman correlation coefficient of 0.57 using experienced dentist for occlusal caries assessments. They have suggested that bitewing radiographs should be combined to visual examination for occlusal caries detection. However, Ekstrand et al. [31] and Ricketts et al. [37] had shown moderate values for Spearman's correlation coefficient, ranging between 0.76 and 0.78 , for the bitewing radiographic examination.

Concerning ROC analysis, at $\mathrm{D}_{1}$ threshold, group $\mathrm{D}$ presented the highest area under the ROC curve when compared to the others. At $\mathrm{D}_{3}$ threshold, groups $\mathrm{B}, \mathrm{C}$, and $\mathrm{D}$ presented higher area under the ROC curve, with no statistically significant difference. This result shows that the examiner's experience has influenced the accuracy of the radiographic examination. The area under the ROC curve represents the probability that a random pair of normal and carious surfaces will be correctly ranked as to their disease state [38]. The larger is area under the ROC curve, the more accurate is the diagnostic process achieved by that group [11]. According to Nytun et al. [39], ROC method revealed a statistically significant difference between combined visual-radiographic examination and the two other but not between the isolated visual or radiographic examination. In this study, the area under the ROC curve was low to moderate for all the four groups for $\mathrm{D}_{1}$ (ranging from 0.478 to 0.573 ) and $\mathrm{D} 3$ (ranging from 0.557 to 0.646 ) thresholds. The wide range of areas under the ROC curves indicates that radiographic examination for occlusal caries detection can be very worrying, even when practiced by experienced professionals. The results of ROC analysis on the data from radiographic examination concerning occlusal caries detection have previously been reported a moderate area under the ROC curve (ranging from 0.51 to 0.61 ) by Verdonschot et al. [40] and Angnes et al. [41]. However, previous laboratory studies have shown good values (from 0.71 to 0.72$)[27,34,42]$. This difference could be explained by the comparatively high prevalence of large dentinal lesions in their sample and also by the different techniques regarding standardization recording and X-ray development.

In the present study, radiographic examination yielded lower interexaminer reproducibility, mainly among the dental students and the dental practitioners. However, dentists from group D presented the highest interexaminer agreement. This lower reproducibility is consistent with previous studies $[11,12]$. It has been shown that education and clinical experience increase interexaminer reproducibility in radiographic detection of occlusal caries [12]. In our study, both Brazilian and Swiss dentists were general dental practitioners with 5 to 7 years of experience, and they had the same education as described earlier. This also could be seen concerning the intraexaminer reproducibility, in which dental practitioners presented highest agreement when compared to the dental students for both countries. According to Bader and Shugars [43], the low agreement level might be a reflection of the multitude of factors involved in caries detection and treatment decision. In our study, five factors could be related: age, training, skills, preferences, and experiences, as also described by Lazarchik et al. [12].

Some researchers have been studying the effect of extra training to perform radiographic examination. Gröndahl [44] reported that Swedish dental students in the last year of the dental school performed diagnosis of approximal caries from bitewing radiographs as well as dental radiologists after the students had received additional training. According to Firestone et al. [11], a didactic instruction associated with clinical experience provides students with skills in the detection of approximal caries from bitewing radiographs similar to that of faculty dentists. In our study, no training was given to the dental students before the radiographic examination. We just tested their skills acquired during their dental education to detect occlusal caries from bitewing radiographs.

In conclusion, based on the methodology employed in this work and on the results evaluated and discussed, the reproducibility and the validity of radiographic examination were influenced by the dental education, training, and clinical experience of the examiners in detecting occlusal caries. The great disparity among the groups in the present study indicates that caution must be taken when decisions are made regarding restoration when based only on bitewing radiographs, especially regarding dentine caries lesions. This study reinforces the necessity of improvement of the detection methods that could lead to coherent decisions of treatment with minimum intervention. Caries detection is controversial among students and professionals and requires constant retraining, updating, and information due to the caries pattern and behaviors changes.

Acknowledgments The authors wish to thank the examiners of this research and the Department of Preventive, Restorative, and Pediatric Dentistry, School of Dental Medicine, University of Bern, Bern, Switzerland and the Department of Pediatric Dentistry, School of 
Dentistry of Araraquara, São Paulo State University (UNESP), Araraquara, SP, Brazil for technical support.

Conflict of interest The authors declare that they have no conflict of interest.

\section{References}

1. Bader JD, Shugars DA (2004) A systematic review of the performance of a laser fluorescence device for detecting caries. $\mathrm{J}$ Am Dent Assoc 135:1414-1426

2. Espelid I, Tveit AB, Fjelltveit A (1994) Variations among dentists in radiographic detection of occlusal caries. Caries Res 28:169175

3. Dove SB (2001) Radiographic diagnosis of dental caries. J Dent Educ 65:985-990

4. Kidd EAM, Naylor MN, Wilson RF (1992) Prevalence of clinically undetected and untreated molar occlusal dentine caries in adolescents on the Isle of Wight. Caries Res 26:397-401

5. Weerheijm KL, Groen HJ, Bast AJJ, Kieft JA, Eijkman MAJ, van Amerongen WE (1992) Clinically undetected occlusal dentine caries: a radiographic comparison. Caries Res 26:305-309

6. Richardson PS, McIntyre IG (1996) The difference between clinical and bitewing detection of approximal and occlusal caries in Royal Air Force recruits. Community Dent Health 13:65-69

7. Weerheijm KL (1997) Occlusal "hidden caries". Dent Update 24:182-184

8. Espelid I, Tveit AB (2001) A comparison of radiographic occlusal and approximal caries diagnoses made by 240 dentists. Acta Odontol Scand 59:285-289

9. Wenzel A, Fejerskov O (1992) Validity of diagnosis of questionable caries lesions in occlusal surfaces of extracted third molars. Caries Res 26:188-194

10. Syriopoulos K, Sanderink GC, Velders XL, van der Stelt PF (2000) Radiographic detection of approximal caries: a comparison of dental films and digital imaging systems. Dentomaxillofac Radiol 29:312-318

11. Firestone AR, Lussi A, Weems RA, Heaven TJ (1994) The effect of experience and training on the diagnosis of approximal coronal caries from bitewing radiographs. A Swiss-American comparison. Schweiz Monatsschr Zahnmed 104:719-723

12. Lazarchik DA, Firestone AR, Heaven TJ, Filler SJ, Lussi A (1995) Radiographic evaluation of occlusal caries: effect of training and experience. Caries Res 29:355-358

13. Wrbas K-Th, Kielbassa AM, Schulte-Mönting J, Hellwig E (2000) Effects of additional teaching of final-year dental students on their radiographic diagnosis of caries. Eur J Dent Educ 4:138-142

14. Lussi A, Reich E (2005) The influence of toothpastes and prophylaxis pastes on fluorescence measurements for caries detection. Eur J Oral Sci 113:141-144

15. Hala LA, Mello JB, Carvalho PL (2006) Evaluation of the effectiveness of clinical and radiographic analysis for the diagnosis of proximal caries for different clinical experience levels: comparing lesion depth through histological analysis. Braz J Oral Sci 5:1012-1017

16. Lussi A, Imwinkelried S, Pitts NB, Longbottom C, Reich E (1999) Performance and reproducibility of a laser fluorescence system for detection of occlusal caries in vitro. Caries Res $33: 261-266$

17. Lin LIK (1989) A concordance correlation coefficient to evaluate reproducibility. Biometrics 45:255-268

18. Taylor BN, Kuyatt CE (1994) Guidelines for evaluating and expressing the uncertainty of NIST measurement results. NIST Technical 14-15
19. Fleiss IL (1981) Statistical methods for rates and proportions, 2nd edn. Wiley, New York

20. Mileman PA, van den Hout WB (2002) Comparing the accuracy of Dutch dentists and dental students in the radiographic diagnosis of dentinal caries. Dentomaxillofac Radiol 31:7-14

21. Swenson E, Hennessy B (2009) Detection of occlusal carious lesions: an in vitro comparison of clinicians' diagnostic abilities at varying levels of experience. Gen Dent 57:60-66 quiz 67-68, 95-96

22. Berry HMJ (1983) Cervical burnout and Mach band: two shadows of doubt in radiologic interpretation of carious lesions. J Am Dent Assoc 106:622-625

23. Kay EJ, Watts A, Paterson RC, Blinkhorn AS (1988) Preliminary investigation into the validity of dentists' decisions to restore occlusal surfaces of permanent teeth. Community Dent Oral Epidemiol 16:91-94

24. Kay EJ, Knill-Jones R (1992) Variation in restorative treatment decisions: application of receiver operating characteristic curve (ROC) analysis. Community Dent Oral Epidemiol 20:113-117

25. Rocha ASPS, Almeida SM, Bóscolo FN, Haiter Neto F (2005) Interexaminer agreement in caries radiographic diagnosis by conventional and digital radiographs. J Appl Oral Sci 13:329-333

26. Deep P, Petropoulos D (2003) Effect of illumination on the accuracy of identifying interproximal carious lesions on bitewings radiographs. J Can Dent Assoc 69:444-446

27. Rodrigues JA, Hug I, Diniz MB, Lussi A (2008) Performance of fluorescence methods, radiographic examination and ICDAS II on occlusal surfaces in vitro. Caries Res 42:297-304

28. Russell M, Pitts NB (1993) Radiovisiographic diagnosis of dental caries: initial comparison of basic mode video prints with bitewing radiography. Caries Res 27:65-70

29. Ricketts DN, Whaites EJ, Kidd EA, Brown JE, Wilson RF (1997) An evaluation of the diagnostic yield from bitewing radiographs of small approximal and occlusal carious lesions in a low prevalence sample in vitro using different film types and speeds. Br Dent J 182:51-58

30. Ashley PF, Blinkhorn AS, Davies RM (1998) Occlusal caries diagnosis: an in vitro histological validation of the electronic caries monitor (ECM) and other methods. J Dent 26:83-88

31. Ekstrand KR, Ricketts DN, Kidd EA (1997) Reproducibility and accuracy for assessment of demineralization depth of the occlusal surface: an in vitro examination. Caries Res 31:224-231

32. Lussi A, Firestone A, Schoenberg V, Hotz P, Stich H (1995) In vivo diagnosis of fissure caries using a new electrical resistance monitor. Caries Res 29:81-87

33. Ricketts D, Kidd E, Smith B, Wilson R (1994) Radiographic detection of occlusal caries: effect of X-ray beam factors on diagnosis. Eur J Prosthodont Restor Dent 2:149-154

34. Wenzel A, Verdonschot EH, Truin GJ, König KG (1992) Accuracy of visual inspection, fiber-optic transillumination, and various radiographic image modalities for the detection of occlusal caries in extracted non-cavitated teeth. J Dent Res 71:1934-1937

35. Pitts NB, Fyffe HE (1991) Scottish dentists' use and opinions regarding bitewing radiography. Dentomaxillofac Radiol 20:214-218

36. Downer MC (1989) Validation of methods used in dental caries diagnosis. Int Dent J 39:241-246

37. Ricketts DN, Ekstrand KR, Kidd EA, Larsen T (2002) Relating visual and radiographic ranked scoring systems for occlusal caries detection to histological and microbiological evidence. Oper Dent 27:231-237

38. Hanley JA, McNeil BJ (1982) The meaning and use of the area under a receiver operating characteristic (ROC) curve. Radiology 143:29-36

39. Nytun RB, Raadal M, Espelid I (1992) Diagnosis of dentin involvement in occlusal caries based on visual and radiographic examination of the teeth. Scand J Dent Res 100:144-148 
40. Verdonschot EH, Wenzel A, Bronkhorst EM (1993) Assessment of diagnostic accuracy in caries detection: an analysis of two methods. Community Dent Oral Epidemiol 21:203-208

41. Angnes V, Angnes G, Batistella M, Grande RHM, Loguercio AD (2005) Clinical effectiveness of laser fluorescence, visual inspection and radiography in the detection of occlusal caries. Caries Res 39:490-495
42. Verdonschot EH, Wenzel A, Truin GJ, König KG (1993) Performance of electrical resistance measurements adjunct to visual inspection in the early diagnosis of occlusal caries. J Dent 21:332-337

43. Bader JD, Shugars DA (1992) Understanding dentists' restorative treatment decisions. J Public Health Dent 52:102-110

44. Gröndhal HG (1979) Some factors influencing observer performance in radiographic caries diagnosis. Swed Dent J 3:157-172 